\title{
Is Volunteering Rewarding in Itself?
}

\author{
By STEPHAN MEIER* and ALOIS STUTZER** \\ * Center for Behavioral Economics and Decision-Making at the Federal Reserve Bank of Boston \\ ** Department of Economics, University of Basel
}

September 6, 2006

\begin{abstract}
Volunteering constitutes one of the most important pro-social activities. Following Aristotle, helping others is the way to higher individual well-being. This view contrasts with the selfish utility maximizer who avoids costs from helping others. The two rival views are studied empirically. We find robust evidence that volunteers are more satisfied with their life than nonvolunteers. The issue of causality is studied based on the collapse of East Germany and its infrastructure of volunteering. People who lost their opportunities for volunteering are compared to people who experienced no change in their volunteer status.
\end{abstract}

JEL classification: D64, I31, J22, Z13

Keywords: happiness, pro-social behavior, subjective well-being, volunteering 


\section{TWO VIEWS ON PRO-SOCIAL BEHAVIOR AND HAPPINESS}

The question about what ultimately causes people's happiness is found throughout the history of ideas. Greek philosophers were already debating how people can and should achieve happiness. Basically two views concerning the pursuit of happiness evolved. The first view emphasizes that helping others increases people's happiness. Referring to Aristotle, it is stated that true happiness is to be found in the expression of virtue. A happy person is therefore a moral person. ${ }^{1}$ The second view emphasizes that people who pursue their narrow self-interest become happy. A homo oeconomicus, who maximizes his or her utility by behaving selfishly, is expected to be happier than people who accept costs to help others. The hedonistic way to seek pleasure and happiness solely for oneself leads, according to this view, to higher subjective well-being.

In the end, the philosophical question, about whether sacrificing time and money to help others is rewarding and reflected in people's happiness, turns into an empirical question. To discriminate between the two rival views on pro-social behavior and happiness empirically, a measure of people's individual well-being is needed. We propose reported subjective well-being as a proxy measure. Based on extensive research by psychologists over the last decades (see Diener et al., 1999; Kahneman et al., 1999), the measurement of subjective well-being has made great progress. In recent years, a major new development in economics takes advantage of these survey measures to test old hypotheses in a completely new way (see, e.g., the surveys by Frey and Stutzer, 2002a, b and Layard, 2005).

We investigate empirically whether individuals who volunteer are more satisfied with their life. The paper concentrates on volunteer work because it constitutes one of the most important pro-social activities. In the United States, around 50 percent of all adults do volunteer work, and this constitutes an equivalent of 5 million full time jobs. In Europe, on average 32.1 percent of the population do volunteer work and this constitutes an equivalent of 4.5 million full time jobs

\footnotetext{
${ }^{1}$ In the recent literature in economics, Konow and Early (2002) take up this idea.
} 
(Anheier and Salamon, 1999, p.58). ${ }^{2}$ A lot of charitable organizations crucially depend on the work provided by the large number of volunteers. Many community services only exist because people voluntarily offer their work free of charge. As we will discuss in greater detail later, volunteers might 'help' others for quite different motives. In particular, people might volunteer for intrinsic and/or extrinsic reasons (Menchik and Weisbrod, 1987); and these motives might affect the degree of joy generated by the activity itself.

This paper presents empirical evidence on the relationship between volunteering and life satisfaction, based on the German Socio-Economic Panel (GSOEP) for the period between 1985 and 1999. This large panel data set is one of the best data sets available for studying individual well-being in a longitudinal framework. Individuals are surveyed each year concerning various aspects of their life. In addition to questions about their socio-economic situation, participants are asked about their life satisfaction and the extent of volunteer work they do. Like in previous studies, we find in a raw correlation that volunteers are more likely to report high subjective well-being than non-volunteers. This result, however, does not establish causality. For example, it is likely that unobserved personality characteristics like the degree of extraversion affect volunteering, as well as people's reports on their well-being. Moreover, reversed causality might be involved, i.e. satisfied people are more likely to volunteer. Such causality problems are pervasive in the earlier literature. ${ }^{3}$

Here, we try to get as close as possible to a situation where people's opportunities to volunteer changed by an 'exogenous shock'. We study the issue of causality based on the collapse of the German Democratic Republic (GDR). ${ }^{4}$ Shortly after the fall of the Berlin Wall but before the

\footnotetext{
${ }^{2}$ Comparison of volunteering between countries and even between surveys in the same country is difficult because the definitions of volunteering vary greatly. For the definition and sources used in this paragraph, see Anheier and Salamon (1999).

${ }^{3}$ In the foreword to the special issue on volunteer work in Law and Contemporary Problems, Clotfelter (1999, p.9) points out the problems of many previous studies: "Unfortunately, all of these empirical questions face a daunting methodological problem - the question of causality. If volunteers are found to have systematically different attitudes from those of non-volunteers, for example, it is by no means obvious that volunteering affects attitudes or vice versa. [...] This is not to say that empirical analysis cannot uncover behavioral or attitudinal consequences of volunteering and public service participation, but only that care must be taken to distinguish correlation and causation."

${ }^{4}$ Other studies using the German reunification as an exogenous shock are, e.g., Fuchs-Schündeln and Schündeln (2005) and Redding and Sturm (2005).
} 
German reunification, the first wave of data of the GSOEP was collected in East Germany. Volunteering was still widespread. After the reunification, a large portion of the infrastructure of volunteering (e.g. sports clubs associated with firms and community associations) collapsed and people lost their opportunities for volunteering. The Enquete-Commission of the German Bundestag on the 'Future of Civic Activities' concluded in their report: "More than 37 percent of all the volunteers in the GDR stopped their volunteer work between 1989 and 1991. 50 percent reported that they stopped volunteering due to the termination of groups and organizations which previously provided opportunities for civic engagement, i.e. societal mass organizations or publicly owned firms" (Enquete-Kommission, 2002, p.226; own translation). Based on a comparison of the change in subjective well-being of people in East Germany who lost their opportunity to volunteer and of people from the control group who had no change in their volunteer status, the hypothesis is supported that volunteering is rewarding in terms of higher life satisfaction. We are aware that the German reunification changed people's life in many respects other than the possibilities for volunteering. The general shock is taken into account by only comparing individuals living in East Germany. Moreover, individual changes in life circumstances possibly correlated with the loss of volunteer work, in particular any job loss, are controlled for in the econometric specification. Unobserved changes, of course, have to remain and may still bias our findings. Despite the relative advantages, this indicates the limits of a study based on a large-scale social change rather than a social experiment.

The paper proceeds as follows. Section I discusses the theoretical consideration about why volunteering might influence well-being, as well as the results of previous research. In section II, the empirical analysis is presented in three steps. First, together with the presentation of the data set, the raw correlation between volunteering and reported life satisfaction is established. Second, we discuss the influence of the German reunification on volunteering and use the reunification experience to study the issue of causality. Third, the influence of people's life goals on the reward of volunteering is investigated. Section III offers a summary of the results and concluding remarks. 


\section{HAPPY VOLUNTEERS: THEORETICAL CONSIDERATIONS AND PREVIOUS RESEARCH}

Volunteering can positively affect individuals' well-being due to various reasons. The different channels can be roughly divided into two groups as already classified by Menchik and Weisbrod (1987): (1) People's well-being increases because they enjoy helping others per se. The reward is internally due to an intrinsic motivation to care for others' welfare; (2) People volunteer instrumentally in order to receive a by-product of volunteer work. People do not enjoy volunteering per se but their utility increases because they receive an extrinsic reward from volunteering.

(1) Intrinsic motivation. Volunteers receive an internal reward as a direct result of their activity and/or from the outcome of the volunteer work they do. Because people enjoy helping others, no other (material) reward is necessary to motivate people. Three intrinsic rewards can be distinguished:

a. People care about the recipient's utility. Due to pro-social preferences, people's utility increases either if other people are better off as a result, or if inequality between persons diminishes (for a survey of theories, see Meier, 2007). For example, a person who volunteers in an old people's home enjoys seeing that old people's welfare improves as a result of somebody caring for them. In a survey about the benefits of volunteering, 67 percent of the interviewed volunteers stated that an important source of satisfaction was seeing the results of their work (Argyle, 1999, p.365). However, if seeing the outcome of volunteer work is the only reward, people should free-ride on the volunteering of others who produce the public good (see, e.g. Becker, 1974). Free-riders could enjoy the outcome of volunteering even more when the effort is provided by others.

b. Volunteers benefit from intrinsic work enjoyment (e.g. Deci, 1975; Frey, 1997). Independently of the outcome, people enjoy doing the required task per se, as well as the social interaction with those supported or with other volunteers in the team. For example, people who volunteer for firefighting probably enjoy working in teams to fight fires with 
modern equipment. The task of volunteering may increase people's self-determination and feelings of competence because "[...] intrinsic motivation involves people freely engaging in activities that they find interesting, that provide novelty and optimal challenge" (Deci and Ryan, 2000, p.235). In the end, self-determination and feelings of competence influence subjective well-being positively.

c. The act of helping others gives enjoyment per se. People receive a 'warm glow' (Andreoni, 1990) from contributing time to the provision of a public good. Independently of the outcome, the knowledge of contributing to a good cause is internally self-rewarding. This good feeling may, for example, be due to guilt reduction (Bierhoff, 2002).

(2) Extrinsic reasons. People may also receive utility from helping others because volunteering is extrinsically rewarding. Helping others is then secondary and direct positive feelings from helping others are absent. People volunteer 'instrumentally'; they see volunteering as an investment and expect external benefits or payoffs.

a. Volunteering can be undertaken as an investment in human capital. Individuals engage in volunteer activities to raise future earnings on the labor market (Menchik and Weisbrod, 1987; Hackl et al., 2004). Especially if human capital depreciates due to illness, childbearing or being laid off, volunteering allows for the rebuilding or maintaining of employment skills. Women who have been out of the labor market while giving birth and raising children may, for example, use such a re-entry strategy (e.g. Schram and Dunsing, 1981). People may also volunteer because community service is often the prerequisite for a certain position in a private or a public firm. If volunteering is undertaken due to such extrinsic motivators, the correlation between volunteering and well-being would be due to expectations of higher earnings in the future.

b. People can volunteer in order to invest in their social network. Through engagement in volunteer work, social contacts evolve which can be valuable in establishing business 
contacts or for getting employment. The expected future (material) reward is responsible for the correlation between volunteering and well-being. Politicians may, for example, not only volunteer because they enjoy helping others, but also because they wish to signal their good traits at the same time as hoping to make valuable social contacts for their political career. However, volunteers may also enjoy social interactions without the expectation of an extrinsic reward in the future. In this case, meeting people and making friends, which increase the feeling of relatedness, is not extrinsically but intrinsically rewarding.

c. People might undertake volunteer work to get social approval. The engagement increases their social standing within their reference group. Not only might this increase their expected future (material) rewards, but social approval and prestige can be valuable for itself. Empirical evidence for charitable giving supports the notion that prestige considerations partly motivate people to behave pro-socially (Harbaugh, 1998).

The benefits from volunteering are probably for most people a combination of the aforementioned rewards. Previous research was not able to isolate the aspects of volunteering that are most rewarding. It is even still unclear whether volunteering is increasing people's level of well-being directly at all or whether benefits are solely from extrinsic rewards. Volunteering involves physical effort and has opportunity cost of time; instead of volunteering, people could use the time for market work or leisure activities. With regard to empirical findings, most of the evidence so far is suggestive but not conclusive: Volunteers are less prone to depression (Wilson and Musick, 1999), for elderly volunteers, a positive correlation between volunteering and life satisfaction is found (Wheeler et al., 1998), volunteers' physical health is stronger as they grow older (Stephan, 1991) and, ultimately, volunteers are found to have a lower risk of early mortality (Musick et al., 1999; Oman et al., 1999). ${ }^{5}$ Most of the research on the benefits of volunteering, however, has two shortcomings. First, many studies ask participants of volunteer programs about the benefits of

\footnotetext{
${ }^{5}$ As volunteering is quite different from membership in voluntary associations, studies on the effect of membership on life satisfaction are not reported here.
} 
volunteering. The result that people indicate enjoyment as one of the benefits is not surprising, given that they have chosen it. Moreover, the result might be due to the fact that participants are more optimistic than average people or that they wish to justify their volunteer work. Second, most studies use cross-sectional data. Such an empirical strategy, of course, makes any conclusions about causality very difficult, because volunteers and non-volunteers may differ in many respects other than volunteer status.

Two empirical directions can be undertaken instead:

(1) The effect of pro-social behavior on subjective well-being can be investigated in the laboratory. Charness and Grosskopf (2001) and Konow and Earley (2002) are two related laboratory experimental studies. In the former study based on dictator games, no relation between well-being and pro-social behavior was found. The latter study only detected a relationship between long-term subjective well-being and generosity in a dictator game. The question of causality cannot be answered. In addition, whether pro-social behavior increases individuals' utility is difficult to measure in the laboratory because measures of overall well-being are explicitly designed not to be sensitive to minor life events. The low stakes involved in a laboratory experiment should therefore not be expected to influence reported life satisfaction. ${ }^{6}$

(2) Field studies can inform about the effect of pro-social behavior and subjective well-being. However, the data has to be better suited for the question at hand than in previous studies. More recent field studies use longitudinal survey data and investigate whether volunteering ten years ago has an influence on people's risk of mortality or depression scores today. The results support the view that volunteering is positively correlated with physical and mental health (for an overview, see Wilson and Musick, 1999). Thoits and Hewitt (2001) present a study which is similar to the analysis in this paper: they use the panel structure of two waves of a US survey to estimate whether

\footnotetext{
${ }^{6}$ A number of experimental studies interpret subjects' pro-social behavior as driven by a psychic reward. For example, Andreoni (1995) assumes that people receive a 'warm glow' feeling from pro-social behavior, which can partly explain their behavior. However, he does not try to measure this feeling directly.
} 
volunteering has an influence on various measures of well-being like life satisfaction, self-esteem, health and depression. To test for selection effects, the authors control for past reported well-being. The results show, on the one hand, that volunteers report higher well-being than non-volunteers and, on the other hand, that past well-being is correlated with present volunteering. The limits of this study are that the correlation could be spurious due to unobserved individual heterogeneity. Moreover, people's well-being may have increased between the two waves due to a third factor which simultaneously increased volunteering.

The empirical approach in this paper has at least two advantages over previous studies. First, we can rely on a large panel data set, including many more individual observations than analyzed in other studies and spanning a fourteen years' period, which includes eleven waves of the survey. This panel structure allows us to address important selection effects due to unobserved personal characteristics. For example, more outgoing personalities report, on average, higher satisfaction scores and they are at the same time more likely to volunteer. Without controlling for individual heterogeneity using fixed-effects models, a spurious correlation between volunteering and reported well-being could emerge. The systematic use of panel data is an important step towards more rigorous causal inference in research on subjective well-being. Second, the collapse of the GDR offers new possibilities for studying causality. The analyzed intervention comes close to a random manipulation of the extent of volunteering. Thus, the effect on well-being for people affected by the intervention compared with people not affected by the loss of possibilities for volunteering can be investigated.

\section{EMPIRICAL ANALYSIS}

\section{III.1 Data}

For the analysis on whether volunteering increases people's well-being, large-scale survey data from the German Socio-Economic Panel (GSOEP) is used. In the period between 1985 and 1999, around 22'000 different individuals were interviewed on various aspects of their socio-economic 
status and on their demographic characteristics. Moreover, the individuals were asked about their life satisfaction and the extent of their volunteer work. Importantly, while answering the question about life satisfaction, volunteering is not salient in the GSOEP. In most other survey studies used in research on volunteering, the whole focus is on volunteer work and the benefits derived from it. It is a more powerful test of the rewards of volunteering if the benefits are reflected in a very general measure of subjective well-being, like the one used in the GSOEP. In the following section, the features of the questions about volunteering and life satisfaction are presented.

Volunteering is captured by the following question in the section on spare time activities: "Did you perform volunteer work?" Individuals can answer this question on a four-point scale (4 "weekly", 3 "monthly", 2 "less frequently" and 1 "never"). Figure 1 shows the distribution of the frequency of volunteering based on the individuals surveyed in Germany between 1985 and $1999 .^{7}$

[Figure 1 about here]

The distribution shows that around 28 percent of all men volunteer, whereas only 20 percent of all women volunteer. ${ }^{8}$ In total, 23 percent of the German population volunteer in one form or another. These numbers on the extent of volunteering correspond to results from a study by Anheier and Salamon (1999). If the volunteers are divided into two groups: people who volunteer frequently ("weekly" or "monthly") and people who volunteer rarely ("less frequently" or "never"), 14 percent of the population do volunteer work frequently, whereas 86 percent do volunteer work rarely or never.

Figure 2 shows the proportion of people of volunteering frequently ("weekly" or "monthly") from 1985 until 1999 for both the West and the East German sample. In West Germany, the proportion who volunteers frequently stays about the same over time. Figure 2 also visualizes the dramatic drop in volunteering after the reunification in East Germany. After the fall of the Berlin Wall in 1989, the GSOEP collected the first wave of data in East Germany in 1990, before the German

\footnotetext{
${ }^{7}$ The question on volunteering was included in eleven years but not in the years 1987, 1989, 1991 and 1993.

${ }^{8}$ Individual responses are weighted in order to get a representative distribution using cross-sectional weights.
} 
reunification. The extent of volunteering was substantial: almost 17 percent indicated that they volunteer frequently. Due to the social change with reunification, the frequency of volunteering dropped dramatically: in 1992, when people in East Germany were surveyed about their volunteer work for the second time, only about 9 percent of the respondents indicated that they do volunteer work weekly or monthly, a reduction of 8 percentage points. According to experts, this decline was largely involuntary and the collapse of the infrastructure for volunteering hit people fairly randomly (see discussion in next section). The figure also shows that it takes a while to build up an infrastructure for volunteering. In the years after reunification, the amount of volunteer work gradually increased again, but in 1999 still had not reached the pre-reunification level.

[Figure 2 about here]

Individuals' happiness or life satisfaction is measured with a single-item question on an elevenpoint scale in the GSOEP: "How satisfied are you with your life, all things considered?" Responses range on a scale from 0 "completely dissatisfied" to 10 "completely satisfied". 4.78 percent report to be completely satisfied with life (score $=10)$ and about 44 percent report life satisfaction in the top three categories. However, there are about 5 percent at the bottom of the scale falling into the categories 0 to 3 . On average, people's life satisfaction is at a level of 6.90 on the scale from 0 to 10. For a broader discussion on subjective well-being in general, and on measuring life satisfaction in the GSOEP, see Frijters et al. (2004) and Stutzer and Frey (2004).

\section{III.2 Do Volunteers Report Higher Life Satisfaction?}

Figure 3 presents the correlation between frequency of volunteering and life satisfaction for the pooled data set. The descriptive statistics show a sizable positive relationship between volunteering and life satisfaction. People who never volunteer report, on average, the lowest scores of life satisfaction. For each subsequent category, higher reported life satisfaction is measured. While people who never volunteer report an average life satisfaction of 6.93 points, people who volunteer 
weekly report an average life satisfaction of 7.35 points, i.e. 0.42 point higher. The difference is sizeable and statistically highly significant. ${ }^{9}$ Dividing people into two groups, people who volunteer weekly or monthly report, on average, to be satisfied with their life at a level of 7.30 , whereas people who volunteer less frequently or never, report, on average, a score of only 6.95. The difference of 0.35 point is again statistically significant at the 99 percent level.

[Figure 3 about here]

The raw correlation between volunteering and life satisfaction scores does not take into account that a third factor may influence both the frequency of volunteering, as well as reported subjective wellbeing. For example, income may influence subjective well-being positively, but may simultaneously affect the propensity to volunteer (e.g. Prouteau and Wolff, 2004). The positive correlation between volunteering and life satisfaction may therefore just reflect differences in the socio-economic status and in the demographic characteristics of people. To control for individual characteristics, we use a multivariate regression approach.

[Table 1 about here]

Table 1 presents in panel A the relationship between life satisfaction scores as the dependent variable and the frequency of volunteering as the independent variable, controlling for a number of socio-economic and demographic variables. The four dummy variables from "never volunteering" to "weekly volunteering" capture the frequency of volunteering. In the reference group are individuals who never volunteer. The estimation is based on an ordinary least squares model and the estimated robust standard errors are corrected for repeated observations at the individual level over time. ${ }^{10}$ Panel A indicates that people who volunteer report a higher life satisfaction. Especially if people volunteer weekly or monthly, they report higher satisfaction scores than people who do

\footnotetext{
${ }^{9}$ The differences in means are analyzed using $t$ - tests unless otherwise noted.

${ }^{10}$ The model chosen implicitly assumes that life satisfaction scores can be cardinally interpreted. While the ranking information would require ordered probit or logit models, comparative analyses have shown that it makes virtually no difference whether responses are treated cardinally or ordinally in happiness functions (Di Tella et al., 2001; Hamermesh, 2001). However, ordinary least squares models are easier to interpret. The estimation results of an ordered probit model can be obtained from the authors on request.
} 
not volunteer. The differences are sizable and highly statistically significant. ${ }^{11}$ An individual who volunteers weekly reports, on average, a 0.30 points higher subjective well-being than somebody who never volunteers. People who volunteer monthly report, on average, a 0.26 points higher subjective well-being than the reference group. These results are consistent with the hypothesis that volunteering increases people's utility. The estimated partial correlation is sizeable. It is of similar magnitude as the difference in life satisfaction between singles without a partner and married people (0.25) and about one fourth of the life satisfaction difference between employed and unemployed people (-1.21).

The control variables in table 1 capture many potential differences between volunteers and nonvolunteers, which could be responsible for any difference in life satisfaction. The effects of the control variables are in line with results from other micro-econometric happiness functions for Germany (see, e.g. Stutzer and Frey, 2004). Note, that special attention is given to respondents' involvement in the labor market. Included are people's net hourly wages, as well as their working time. The variables 'wage not available', 'wage not applicable', 'working time not available' and 'working time not applicable' are included because there are many respondents who neither are employed or self-employed. Wage and working time is 0 in these cases. Otherwise, the results for wage and working time would be biased. ${ }^{12}$

As household income and workers' wages are taken into account, the significantly positive effect of volunteering on people's life satisfaction is in line with the hypothesis that volunteers are intrinsically motivated. However, the average effect might hide substantial variation in the benefits from volunteering across people. There might well be some people volunteering for instrumental reasons (see the extended discussion in section 3.4). Extrinsically motivated volunteers may,

\footnotetext{
11 'Monthly volunteering' and 'Weekly volunteering' also differ from 'Less than monthly volunteering' ( $p<0.001$ in an $F$ - test). The difference between 'Monthly volunteering' and 'Weekly volunteering' is not statistically significant.

${ }^{12}$ Results for the effect of volunteering on subjective well-being do not change if people are excluded who are working but whose wage and working time is not available. As wages are not available for the East German sample in 1990, we estimated both models in table 1 excluding people living in East Germany. The results do not change.
} 
moreover, benefit in other dimensions than income that are not taken into account in the estimation. Therefore, we do not want to over-interpret the finding with regard to volunteers' motives.

The regression in panel A, however, does not control for unobserved time-invariant individual differences. For example, more outgoing personalities are more likely to volunteer and to report high subjective well-being. The panel structure of the GSOEP allows for the control of such spurious correlations due to unobserved individual heterogeneity by using a model with individual fixed-effects. Following this approach, we loose, however, the positive effect of volunteering on life satisfaction for those who benefit the most and therefore always volunteer. Their life satisfaction is never observed in the panel in the alternative state of not volunteering. Their life satisfaction differential due to volunteering thus cannot be identified in the fixed-effects approach. ${ }^{13}$ Accordingly, the estimated effects are expected to be smaller in the fixed-effects estimation.

Panel B in table 1 reports the results of the ordinary least squares estimation with individual fixedeffects. While the effects indeed are smaller, an individual who volunteers weekly still reports, on average, a 0.08 point higher subjective well-being than an individual who never volunteers, controlling for unobservable individual heterogeneity. The difference is statistically significant at the 99 percent level. The effect remains robust if volunteering is measured with a dummy variable that equals 1 if an individual volunteers weekly or monthly and 0 if an individual volunteers less often or never. This variable probably best captures the important difference in the frequency of volunteering, whether people volunteer often and regularly or whether people very seldom or never volunteer. People who volunteer frequently report, on average, a 0.055 points higher life satisfaction $(p<0.002){ }^{14}$

\footnotetext{
${ }^{13}$ It is, however, possible to test whether the difference in life satisfaction between people who always volunteer and those who never volunteer changes over time by interacting the year dummies with a dummy whether people always or never volunteer. The results (available on request) show no systematic time trend in the effect of volunteering.

${ }^{14}$ The full estimation is not presented here, but can be obtained from the authors on request. The positive relationship between volunteering and life satisfaction remains if we estimate the effects for working and non-working people separately. However, for the worker sample, the effect is statistically significant only on the 90 percent level. For the non-worker sample, it remains statistically significant on the 99 percent level. We have no handy post hoc explanation why the standard error for volunteering is larger in the worker sample than in the non-worker sample. However, it
} 
However, whether volunteers report higher life satisfaction because helping others makes people happy or because people who become happier start volunteering cannot be answered based on the results of the fixed-effects estimations. To further study the question of causality, a situation is analyzed where, due to an exogenous shock, some people lose the possibility of volunteering. If they report, ceteris paribus, lower life satisfaction afterwards, the effect is more likely to be causal. If there is no change in subjective well-being, previous findings reflect to a large extent third factors and reverse causality.

\section{III.3 An Attempt to Make Causal Inference: German Reunification and the Abrupt Decline in Volunteering}

The German reunification constitutes an event, which exogenously changed the situation for many volunteers in the former GDR. After the breakdown of the GDR, a large fraction of the infrastructure for volunteering collapsed (see figure 2). In East Germany, where volunteering was widespread, many opportunities were linked with the old structures, e.g. sports clubs were connected with nationally owned companies. Due to the reunification, these structures disappeared and many volunteers were 'forced' to stop volunteering. "With transformation, the infrastructure of volunteering lost its basis because community services in the GDR were to a large extent connected to publicly owned companies and institutions (schools etc.). Large companies especially, as the providers and supporters of an infrastructure of civic engagement (e.g. in sports), disappeared with the breakdown of the GDR-industry" (Gensicke, 2000, p.178; own translation). This assessment is similar to the conclusion of the Enquete-Commission cited in the introduction and repeated here that " $[\mathrm{m}]$ ore than 37 percent of all the volunteers in the GDR stopped their volunteer work between 1989 and 1991. 50 percent reported that they stopped volunteering due to the termination of groups and organizations which previously provided opportunities for civic engagement, i.e. societal mass organizations or publicly owned firms" (Enquete-Kommission, 2002, p.226; own translation).

might be that there is more variation in the motivation of volunteers in the former group, leading also to a larger variation in benefits. 
What has been the effect of this exogenous shock on the subjective well-being of former volunteers?

After the reunification, average life satisfaction decreased in East Germany (Frijters et al., 2004). If volunteering influences well-being positively, the decrease of life satisfaction is expected to be larger for people who lost their opportunity for volunteering due to the collapse of the volunteer infrastructure. Figure 4 compares the life satisfaction of the same people in 1990 and in 1992, depending on their volunteer status. Importantly, only people living in East Germany in both periods are included as they are exposed to the same general change in circumstances between 1990 and 1992. The life satisfaction of people who neither in 1990 nor in 1992 did volunteer work frequently (category = "never volunteer"; $\mathrm{N}=2,615$ ) decreases to almost the same extent as for people who volunteered frequently in 1990 and were still able to carry out volunteer work in 1992 (“always volunteer”; $\mathrm{N}=224$ ). However, volunteers report higher well-being levels in both years. Life satisfaction does not decrease as much for those who started volunteering between 1990 and $1992(\mathrm{~N}=109)$. However, we do not know why these people start volunteering and therefore the it is difficult to attribute the change in life satisfaction to the take up of volunteer work. Finally, the most important group: individuals who stopped volunteering ("stop volunteer"; $\mathrm{N}=431$ ). For them, life satisfaction decreases substantially. While the life satisfaction of people who did not change their volunteer status ("always volunteer" or "never volunteer") decreases by 0.53 points (s.e.= 0.004; $\mathrm{N}=2,839$ ), the life satisfaction of people who stopped volunteering decreases by 0.72 points (s.e. $=0.10 ; \mathrm{N}=431$ ). The difference of -0.19 points is statistically significant at the 90 percent level $(\mathrm{t}=1.70)$. The life satisfaction of people who volunteered frequently in 1990 drops from the high level experienced by those who volunteer down to the level that is reported by non-volunteers. This result supports the interpretation that volunteering positively affects life satisfaction. The effect itself is sizeable. It amounts to about one fifth of the difference in life satisfaction between employed and unemployed people in East Germany.

[Figure 4 about here] 
We see three possible objections to the simple difference-in-difference analysis:

(1) Other factors might affect both volunteer work and life satisfaction. For example, people who become unemployed are less likely to volunteer and at the same time report lower life satisfaction. For the two-period sample used here, a change in the employment status means loss of work. Nobody in the relevant period changed from being unemployed to being employed. Moreover, unemployment rates are also similar in 1992 in both groups: 7.1 percent in the group of people who 'always volunteer' and 8.8 percent in the group of people who 'stopped volunteering' $(p>0.46)$. In panel A of table 2, a multivariate regression is presented which includes individual fixed-effects and which controls for a number of socio-economic and demographic variables, most importantly changes in the employment status. ${ }^{15}$ Only people from East Germany are included, for whom the volunteer status and the life satisfaction scores for 1990 and 1992 are known. People who started volunteering after the reunification (category = "start volunteer") are excluded from the estimation because their inclusion would hamper causal inference. As only two years are included in the model, the negative coefficient of year dummy 1992 indicates that life satisfaction was 0.23 points lower in 1992 than before reunification in 1990, but after the fall of the Berlin Wall in November 1989. This difference is difficult to interpret but might reflect the euphoria about the reunification in 1990. Most importantly, the well-being of individuals who probably involuntarily gave up volunteering decreases even more controlling for observed and unobserved individual heterogeneity. The coefficient of the variable weekly or monthly volunteering is statistically significant at the 95 percent level. The magnitude of the effect is comparable to the one observed in the descriptive statistics: people who lost their volunteer opportunities report a 0.24 points larger drop in life satisfaction than people who did not change their volunteer status. This result supports

\footnotetext{
${ }^{15}$ Wages and income is not included in the regression anymore because no comparable income data for the pre reunification period is available.
} 
the causal interpretation that life satisfaction is influenced positively by volunteering and so refutes the first objection. ${ }^{16}$

[Table 2 about here]

(2) An alternative interpretation of the loss in life satisfaction of people who were no longer in the group of volunteers in 1992 could throw doubt on the direction of causality and in particular upon the reason put forward for the decline in volunteering: many individuals may not have been able to bear the insecurity that came with the breakdown of the communist GDR. These people may have retreated from society and become lethargic. As a result, they also stopped volunteering, but their lower well-being is actually caused by their insecurity. There are, however, at least two counterarguments. First, it is known that many volunteers did not give up because they retreated from society but because the institution for which they used to volunteer disappeared after the reunification. Second, in panel B of table 2, we include the answers to a question on people's insecurity ("The circumstances have become so complicated that I'm barely able to cope with it all"). The dummy variables take the value 1 if people report that the statement does apply and 0 otherwise. The results indicate that people report lower life satisfaction if they feel insecure with respect to the circumstances. However, insecurity does not seem to affect the influence of volunteering on life satisfaction. Volunteering has a robust independent effect on life satisfaction.

(3) Another interpretation of the effect could speculate whether people who were engaged in voluntary work in the GDR were associated with the old political system. After the collapse of the GDR, not only did they lose their voluntary work, but they also primarily lost the connection with the regime. It can be hypothesized that this would have resulted in a loss of status and future perspectives. The empirical validity of this interpretation is analyzed taking the answer to a question in 1990 about satisfaction with the GDR into account. "The following questions deal with the

\footnotetext{
${ }^{16}$ If we check the robustness of this estimation by restricting the sample to people who did not lose their job between 1990 and 1992, the effect remains similar in magnitude (coefficient for 'volunteering weekly or monthly' of $0.21 ; p<$ $0.1)$.
} 
situation in the GDR: All in all, how satisfied or dissatisfied are you with democracy as it exists in the GDR today?" People answered on a four-point scale (1=very satisfied, 2=satisfied, $3=$ dissatisfied, 4=very dissatisfied). An analysis is carried out to gauge whether the effect of volunteering on subjective well-being only applies to people who are more or less satisfied with the regime. If life satisfaction levels are compared in 1990 and 1992, we find that the effects of stopping volunteering on life satisfaction are the same for people who are more or less satisfied with democracy in the GDR (-0.74 points; $\mathrm{N}=164)$ and for people who are more or less dissatisfied with the situation (-0.70 points; $\mathrm{N}=267)$. If separate regressions for two sub-samples (people satisfied/dissatisfied with democracy in the GDR) are run, the effect of volunteering is even higher for people who are more or less dissatisfied with the regime. ${ }^{17}$ This result does not support the interpretation that people who were friendly to the regime lost the most from the fact that volunteering opportunities decreased with the reunification.

In sum, the breakdown of the GDR constitutes a unique situation to analyze the causal effect of volunteering on people's well-being. The results indicate that volunteering does increase happiness. The results are robust when controlling for other factors influencing life satisfaction, like job loss or feelings of insecurity.

How does this result fit into the picture that volunteering in the communist state of East Germany was not always purely voluntary? Imagine that engagement in some sort of community service was expected from a good citizen and a loyal party member. How can one explain that people who might have been 'forced' to volunteer become less happy when they do not have to volunteer anymore? Firstly, the extent of voluntary community services is probably underestimated. Besides the 'official' volunteering, many forms of voluntary community service were known (Gensicke, 2000). Secondly, the fact that people receive a psychic reward even if they were partly required by the system to volunteer is even stronger support for the hypothesis that helping others is rewarding. It could be interpreted that even people who volunteer instrumentally to get a certain job or achieve

\footnotetext{
${ }^{17}$ The estimation results can be obtained from the authors on request.
} 
social recognition will benefit from volunteering directly. Much more research is needed to investigate under which conditions the benefits to the volunteers of volunteering are more or less pronounced. As a first step, the next section presents results on who is likely to benefit the most from volunteering: people who pursue intrinsic life goals or people with extrinsic goals.

\section{III.4 Who Benefits the Most from Volunteering?}

People have different life goals. While some people are more extrinsically oriented ('materialists'), other people put more emphasis on intrinsic life goals. Materialists share the belief that acquisition and possession are central goals on the path to happiness (e.g. Tatzel, 2002 for a discussion in economics). In contrast, people with intrinsic life goals emphasize personal growth, relationships and community spirit as important sources of well-being. Naturally, the question arises whether one set of goals brings more life satisfaction. The research in psychology on this question concludes that 'All Goals Are Not Created Equal' (Ryan et al., 1996), meaning that people with more materialistic goals are less happy than people who pursue intrinsic life goals (see, e.g. Kasser and Ryan, 2001). Applied to pro-social behavior, one could expect that such a 'hedonistic paradox' occurs because people who are materialistically oriented do not help others and therefore do not benefit from the internal rewards of pro-social behavior (Phelps, 2001; Konow and Earley, 2002). As a result, it is not people who pursue their own happiness who become happy but people who care for others.

We address these claims with a focus on volunteering. In two waves of the GSEOP, including both East and West Germans, people were asked "How important for your well-being and satisfaction is ...?" They rated inter alias the following areas: family, friends, income, and career success on a four-point scale. We define the first two areas as intrinsic and the last two as extrinsic. For each person in the sample, the relative importance of extrinsic over intrinsic life goals is calculated, assuming a cardinal scale. ${ }^{18}$ This variable is standardized around the mean, and a proxy for the importance of extrinsic goals is derived with a mean of 0 and a standard deviation of 1 . The higher

\footnotetext{
${ }^{18}$ We calculate the average score for the two extrinsic questions and divide it by the average score of the two intrinsic questions.
} 
the value of the variable, the more weight is given to extrinsic goals. The analysis of the relation between life goals and the effect of volunteering on life satisfaction brings three interesting results:

(1) People who put more emphasis on extrinsic goals compared to intrinsic goals are less satisfied with life. If individuals are divided into two groups at the median, people who put above median importance on extrinsic aspects of life report, on average, a life satisfaction score of 6.8 , while people below the median report a higher score of 7.2 points. The difference of 0.4 points is statistically significant at the 99 percent level. This result for Germany replicates the aforementioned results in psychology that people who pursue extrinsic goals are less satisfied with their life than people focusing on intrinsic life goals.

(2) Volunteers on average do rate intrinsic goals as more important than extrinsic goals. People who volunteer weekly or monthly have an average score of -0.015 , whereas people who volunteer less frequently or never have an average score of 0.002 . The difference is statistically significant at the 95 percent level. Not surprisingly, intrinsically oriented people are more prepared to volunteer. However, also more extrinsically oriented people volunteer. But they may do so due to different reasons. These people may volunteer more instrumentally, i.e. in order to increase the probability of getting a good job or making a political career. For the intrinsic benefits gained from volunteering, such differences in motivations could be important, as indicated by the third result.

(3) People who are more extrinsically oriented benefit less from volunteering than people who put more importance on intrinsic life goals. In panel A of table 3, besides the dummy for volunteering weekly or monthly $(=1)$ or less frequently or never $(=0)$, a variable for the relative importance of extrinsic goals and an interaction between the dummy for volunteering and the relative importance of extrinsic goals is incorporated. The coefficient for the variable relative importance of extrinsic goals supports the first result in a multivariate regression: the more people are extrinsically oriented, the less satisfied they are with their life. The interaction term indicates that people who pursue more extrinsic goals benefit less from volunteering. As the variable for the relative 
importance of extrinsic goals is standardized around the mean, the interaction term indicates that people who are one standard deviation more extrinsically oriented benefit 0.08 points less from volunteering in terms of life satisfaction. The latter result is robust to a specification with individual fixed-effects, which controls for unobserved time-invariant differences between people (panel B of table 3). If separate estimations are run for the highest and the lowest quartile in terms of importance of extrinsic goals, the result becomes even clearer. For the quartile of people who are the most intrinsically oriented, weekly or monthly volunteering increases their life satisfaction, on average, by 0.08 points $($ s.e. $=0.036$ ). For the quartile of people, who are the most extrinsically oriented, there is no statistically significant effect of volunteering on life satisfaction (coefficient=0.02; s.e. $=0.035) .{ }^{19}$ It can therefore be concluded that intrinsically oriented people receive more benefits from volunteering than extrinsically oriented volunteers.

[Table 3 about here]

The differences presented in terms of benefits from volunteering between extrinsically and intrinsically oriented individuals can be interpreted as an indication that the motivation behind volunteering matters. Alternatively, different characteristics of volunteer tasks may be responsible for the difference. More extrinsically oriented people may volunteer, for example, for a political organization, while intrinsically oriented people may volunteer in an old-people's home. More research is needed in order to better understand which volunteer tasks are most rewarding and how such differences can be explained.

\section{CONCLUDING REMARKS}

Helping others increases people's individual well-being. This result is derived from an analysis based on volunteer work and reported subjective well-being for a large panel data set for Germany. People who volunteer frequently are more likely to report high life satisfaction than non-volunteers. The reunification of Germany constitutes an interesting event to investigate the causality of the

\footnotetext{
${ }^{19}$ The full results of the estimations are not presented here, but can be obtained from the authors on request.
} 
relationship between volunteering and happiness. Due to the big changes that took place in civil and firm infrastructure, many volunteers lost their opportunities to be engaged in volunteer work. As a result, we observe that their well-being decreases compared to a control group for which the volunteer status remains unchanged. The result is robust to the introduction of various control variables (like, e.g., job loss) and to the control of time-invariant individual heterogeneity. Importantly, the effect of volunteering is estimated for people who lost their opportunity to volunteer. This reflects the effect of the treatment on the treated but not the population impact. It is therefore an interesting future question whether it applies also to a case where people 'randomly' undertake volunteer work.

The basic result of this study, that volunteering is rewarding for the volunteers in terms of higher life satisfaction, has to be qualified. People who place more importance on extrinsic life goals relative to intrinsic life goals benefit less from volunteering. This may be due to the fact that volunteering is not internally rewarding if people volunteer instrumentally in order to get a (material) reward like a better job. Another possibility is that more extrinsically oriented people are engaged in different volunteer tasks than intrinsically oriented people, whereby the benefits may depend on the task.

The results presented in this paper point to two open questions for future research. First, the question arises why do not more people volunteer in order to increase their life satisfaction. Many people seem to fail to increase their utility because they are not engaged in volunteering. And related, why do people who lost the opportunity to volunteer in East Germany not look more quickly for other opportunities to volunteer? One explanation could be based on the theory of people mispredicting future utility (Frey and Stutzer, 2007). People make mistakes in predicting utility from activities they experience in the future asymmetrically, i.e. they underestimate the benefits from intrinsic tasks like volunteering while they overestimate the value of e.g. additional income from overtime work. Future research could try to assess whether people really underestimate the intrinsic reward from volunteering. Secondly, there is the question about policy 
conclusions. On the one hand, one might stick to the societal level and think about institutions that provide opportunities for volunteer work. On the other hand, there are many current endeavors from private actors and sometimes also from the state to foster volunteering: for example, a number of academic institutions and private and public enterprises take past community services as a prerequisite for admission to a certain college or for employment in higher positions. However, how do these external incentives affect the benefits volunteers get from volunteering? Is selfactualization still possible when volunteering becomes to some extent instrumental or do the incentives lead to a crowding out of intrinsic motivation (Frey, 1997)? The challenge is in being able to understand under which institutional conditions voluntary work remains rewarding in itself.

\section{ACKNOWLEDGMENTS}

We wish to thank Ed Diener, Christoph Engel, Bruno Frey, Dieter Frey, Simon Lüchinger, Dina Pomeranz, Richard Ryan, participants of the Workshop on Well-Being and Social Capital at Harvard University and participants of the Workshop on Capabilities and Happiness at St. Edmund's College, Cambridge, as well as, two anonymous referees for helpful comments. The views expressed herein are solely those of the authors and not those of the Federal Reserve System or the Federal Reserve Bank of Boston. 


\section{REFERENCES}

ANDREONI, J. (1990). Impure Altruism and Donations to Public Goods: A Theory of Warm-Glow Giving. Economic Journal, 100 (401), 464-77.

(1995). Warm-Glow Versus Cold-Prickle: The Effects of Positive and Negative Framing in Cooperation in Experiments. Quarterly Journal of Economics, 110 (1), 1-21.

ANHEIER, H.K. and SALAMON, L.M. (1999). Volunteering in Cross-National Perspective: Initial Comparisons. Law and Contemporary Problems, 62 (4), 43-65.

ARGYLE, M. (1999). Causes and Correlates of Happiness, In D. Kahneman, E. Diener and N. Schwarz (eds.), Well-Being: The Foundations of Hedonic Psychology. New York: Russell Sage Foundation, 353-73.

BECKER, G.S. (1974). A Theory of Social Interactions. Journal of Political Economy, 82 (6), 1063-93.

BIERHOFF, H.-W. (2002). Prosocial Behaviour. New York: Psychology Press.

CHARNESS, G. and GROSSKOPF, B. (2001). Relative Payoffs and Happiness: An Experimental Study. Journal of Economic Behavior and Organization, 45 (3), 301-28.

CLOTFELTER, C.T. (1999). Why 'Amateurs'? Law and Contemporary Problems, 62 (4), 1-16.

DECI, E.L. (1975). Intrinsic Motivation. New York: Plenum Press.

DECI, E.L. and RYAN, R.M. (2000). The "What" and "Why" of Goal Pursuits: Human Needs and the Self-Determination of Behavior. Psychological Inquiry, 11 (4), 227-68.

DI TELLA, R., MACCULLOCH, R.J. and OSWALD, A.J. (2001). Preferences over Inflation and Unemployment: Evidence from Surveys of Happiness. American Economic Review, 91 (1), $335-41$.

DIENER, E., SUH, E.M., LUCAS, R.E. and SMITH, H.L. (1999). Subjective Well-Being: Three Decades of Progress. Psychological Bulletin, 125 (2), 276-303. 
ENQUETE-KOMMISSION (2002). Bericht - Bürgerschaftliches Engagement: Auf Dem Weg in Eine Zukunftsfähige Bürgergesellschaft. Opladen: Leske + Budrich.

FREY, B.S. (1997). Not Just for the Money. An Economic Theory of Personal Motivation. Cheltenham, UK and Brookfield, USA: Edward Elgar.

FREY, B.S. and STUTZER, A. (2002a). What Can Economists Learn from Happiness Research? Journal of Economic Literature, 40 (2), 402-35.

(2002b). Happiness and Economics: How the Economy and Institutions Affect Well-Being. Princeton and Oxford: Princeton University Press.

(2007). What Happiness Research Can Tell Us About Self-Control Problems and Utility Misprediction. Forthcoming in B.S. Frey and A. Stutzer (eds). Economics and Psychology. A Promising New Cross-Disciplinary Field. Cambridge: MIT Press.

FRIJTERS, P., HAISKEN-DENEW, J.P. and SHIELDS, M.A. (2004). Investigating the Patterns and Determinants of Life Satisfaction in Germany Following Reunification. Journal of Human Resources, 39 (3), 649-74.

FUCHS-SCHÜNDELN, N. and SCHÜNDELN, M. (2005). Precautionary Savings and SelfSelection - Evidence from the German Reunification 'Experiment'. Quarterly Journal of Economics, 120 (3), 1085-120.

GENSICKE, T. (2000). Freiwilliges Engagement in Den Neuen Ländern, In B. von Rosenbladt (Ed.), Ergebnisse Der Repräsentativerhebung 1999 Zu Ehrenamt, Freiwilligenarbeit Und Bürgerschaftliches Engagement [Schriftenreihe Des Bundesministeriums Für Familie, Senioren, Frauen Und Jugend]. Stuttgart: Kohlhammer, 176-85.

HACKL, F., HALLA, M. and PRUCKNER, G.J. (2004). The Fallacy of the Good Samaritan: Volunteering as a Weird Way of Making Money. Mimeo, Department of Economics, Johannes Kepler University of Linz.

HAMERMESH, D.S. (2001). The Changing Distribution of Job Satisfaction. Journal of Human Resources, 36 (1), 1-30. 
HARBAUGH, W.T. (1998). The Prestige Motive for Making Charitable Transfers. American Economic Review, 88 (2), 277-82.

KAHNEMAN, D., DIENER, E. and SCHWARZ, N. (eds.) (1999). Well-Being: The Foundations of Hedonic Psychology. New York: Russell Sage Foundation.

KASSER, T. and RYAN, R.M. (2001). Be Careful What You Wish For: Optimal Functioning and the Relative Attainment of Intrinsic and Extrinsic Goals, In P. Schmuck and K. M. Sheldon (eds.), Life Goals and Well-Being. Towards a Positive Psychology of Human Striving. Kirkland, WA: Hogrefe and Huber, 116-31.

KONOW, J. and EARLEY, J. (2002). The Hedonistic Paradox: Is Homo Economicus Happier? Mimeo, Loyola Marymount University.

LAYARD, R. (2005). Happiness: Lessons from a New Science. New York: Penguin Press.

MEIER, S. (2007). A Survey on Economic Theories and Field Evidence on Pro-Social Behavior, Forthcoming in B.S. Frey and A. Stutzer (eds). Economics and Psychology. A Promising New Cross-Disciplinary Field. Cambridge: MIT Press.

MENCHIK, P.L. and WEISBROD, B.A. (1987). Volunteer Labor Supply. Journal of Public Economics, 32 (2), 159-83.

MUSICK, M., HERZOG, A. and HOUSE, J. (1999). Volunteering and Mortality among Older Adults: Findings from a National Sample. Journal of Gerontology, 54B, S173-S80.

OMAN, D., THORESEN, C.E. and MCMAHON, K. (1999). Volunteerism and Mortality among the Community-Dwelling Elderly. Journal of Health Psychology, 4 (3), 301-16.

PHELPS, C.D. (2001). A Clue to the Paradox of Happiness. Journal of Economic Behavior and Organization, 45 (3), 293-300.

PROUTEAU, L. and WOLFF, F.-C. (2004). Volunteer Work and Labour Supply: Theory and Evidence. Mimeo, Faculté des Sciences Economiques, Université de Nantes.

REDDING, S. and STURM, D. (2005). The Costs of Remoteness: Evidence from German Division and Reunification. CEPR Discussion Paper, No. 5015. 
RYAN, R.M., SHELDON, K.M., KASSER, T. and Deci, E.L. (1996). All Goals Are Not Created Equal: An Organismic Perspective on the Nature of Goals and Their Regulation, In P.M. Gollwitzer and J.A. Bargh (eds.), The Psychology of Action: Linking Cognition and Motivation to Behavior. New York and London: The Guilford Press, 7-26.

SCHRAM, V.R. and DUNSING, M.M. (1981). Influences on Married Women's Volunteer Work Participation. Journal of Consumer Research, 7 (4), 372-79.

STEPHAN, P. (1991). Relationship among Market Work, Work Aspiration and Volunteering: The Case of Retired Woman. Nonprofit and Voluntary Sector Quarterly, 20 (2), 225-36. STUTZER, A. and FREY, B.S. (2004). Reported Subjective Well-Being: A Challenge for Economic Theory and Economic Policy. Schmollers Jahrbuch, 124 (2), 191-231. TATZEL, M. (2002). "Money Worlds" and Well-Being: An Integration of Money Disposition, Materialism and Price-Related Behavior. Journal of Economic Psychology, 23 (1), 103-26. THOITS, P.A. and HEWITT, L.N. (2001). Volunteer Work and Well-Being. Journal of Health and Social Behavior, 42 (2), 115-31.

WHEELER, J.A., GOREY, K.M. and GREENBLATT, B. (1998). The Beneficial Effects of Volunteering for Older Volunteers and the People They Serve: A Meta-Analysis. International Journal of Aging and Human Development, 47 (1), 69-79.

WILSON, J. and MUSICK, M. (1999). The Effects of Volunteering on the Volunteer. Law and Contemporary Problems, 62 (4), 141-68. 


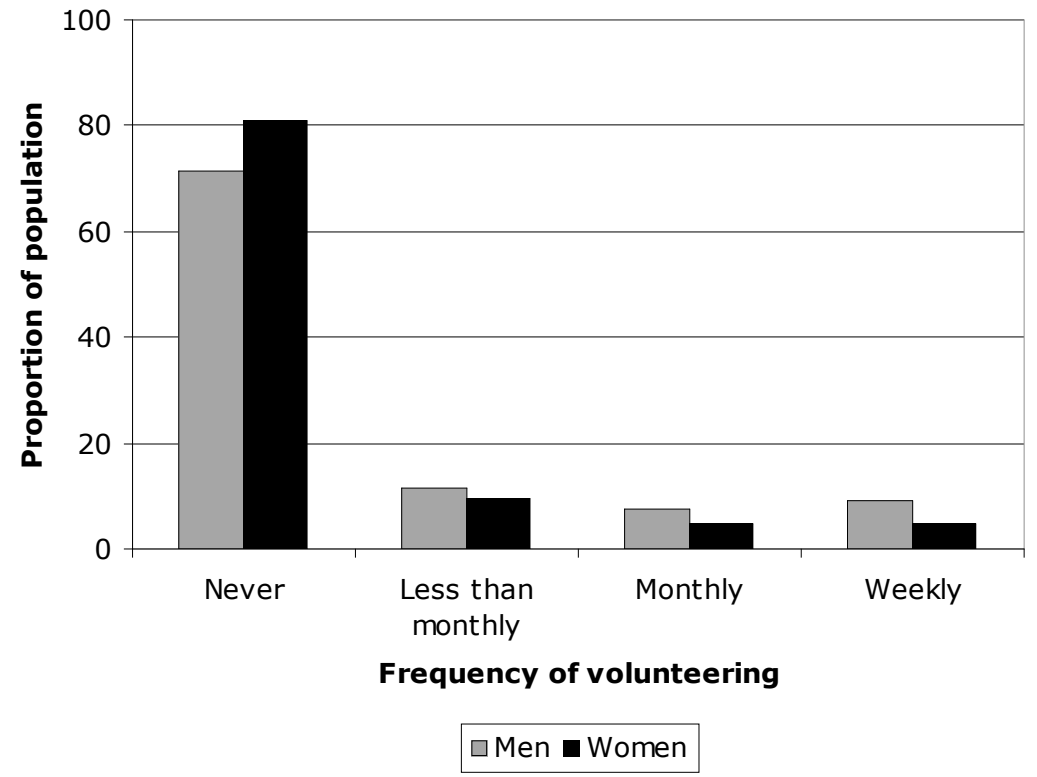

Note: Weighted frequency using individual cross-section weights based on 133'045 observations. Source: German Socio-Economic Panel.

Figure 1: Frequency of Volunteering in Germany, 1985-1999

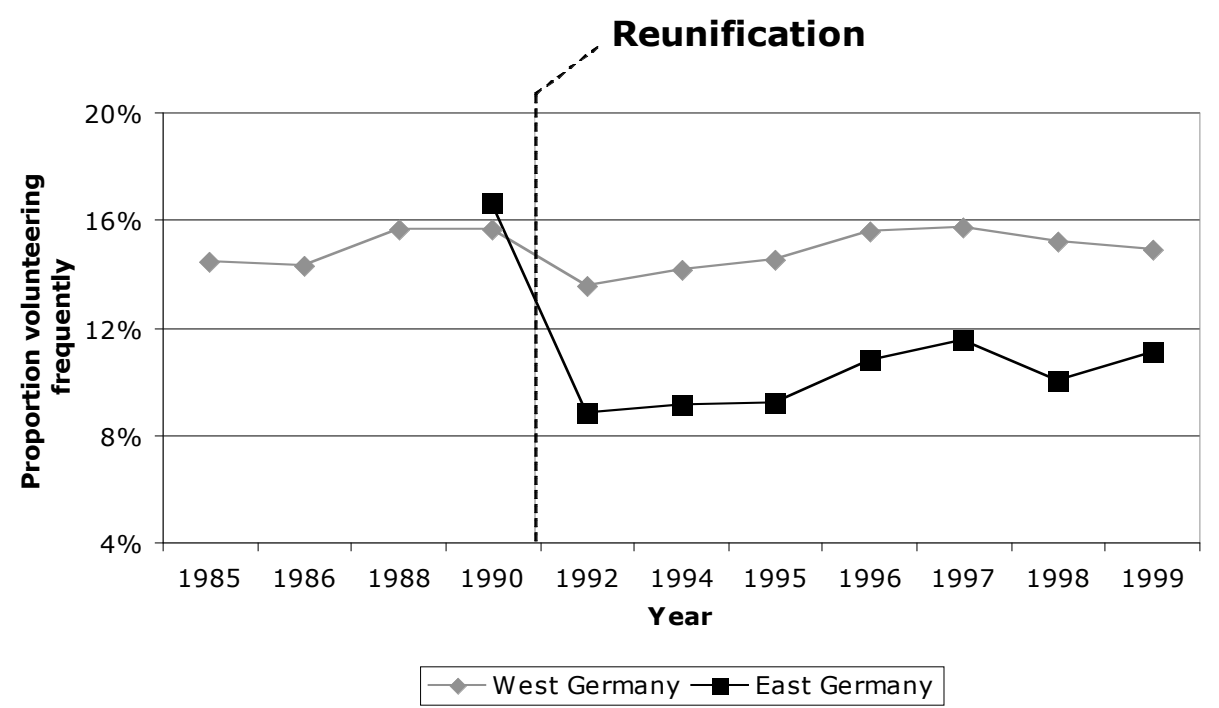

Note: Weighted proportion using individual cross-section weights. Source: German Socio-Economic Panel.

Figure 2: Volunteering in East and West Germany Before and After Reunification 


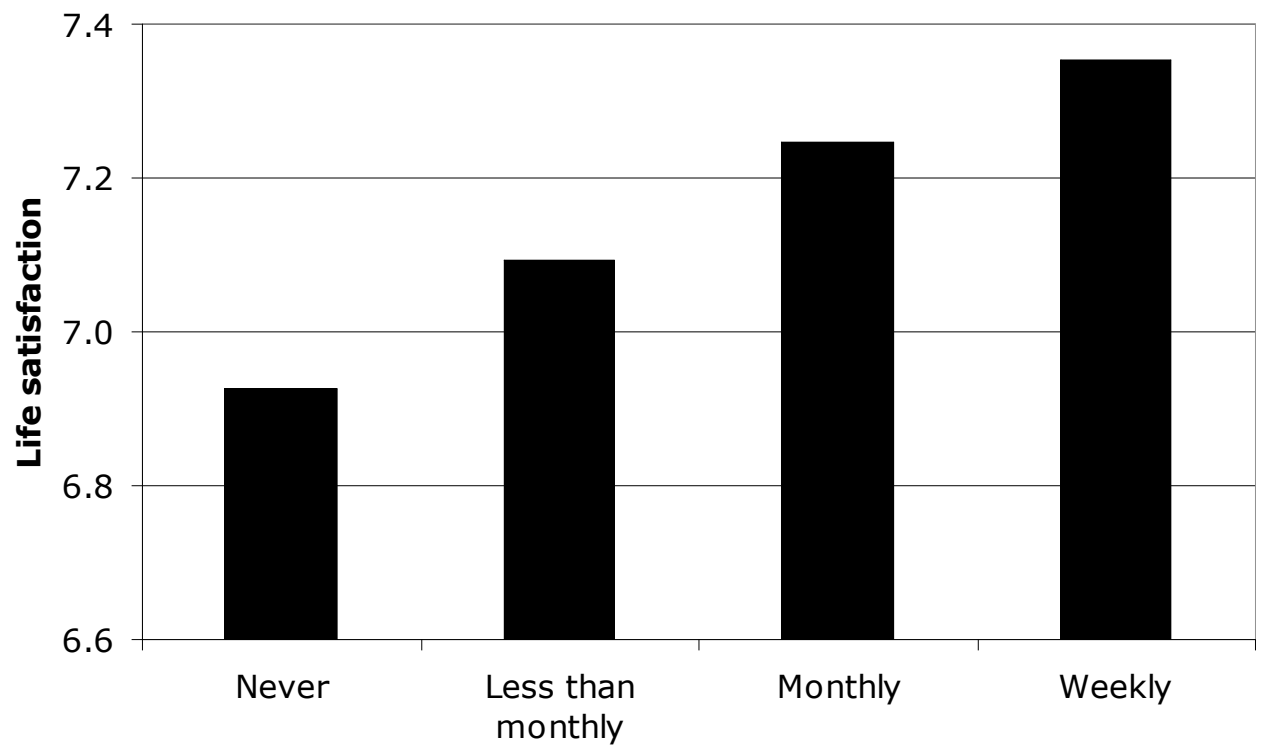

Frequency of volunteering

Source: German Socio-Economic Panel.

Figure 3: Volunteering and Life Satisfaction, Germany 1985-1999

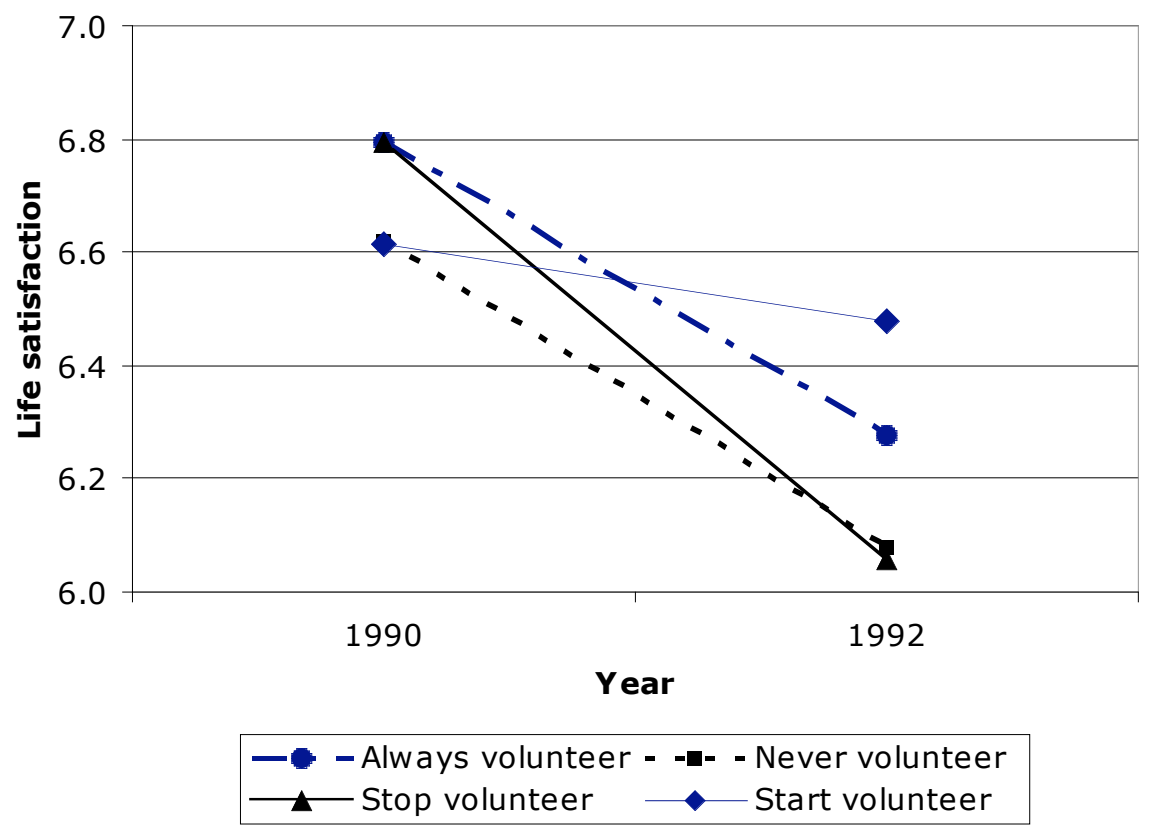

Source: German Socio-Economic Panel.

Figure 4: Loss of Volunteer Work and the Decrease in Life Satisfaction, 1990/92 
Table 1: Life Satisfaction and Volunteering, Germany 1985-1999

Dependent variable: Satisfaction with life

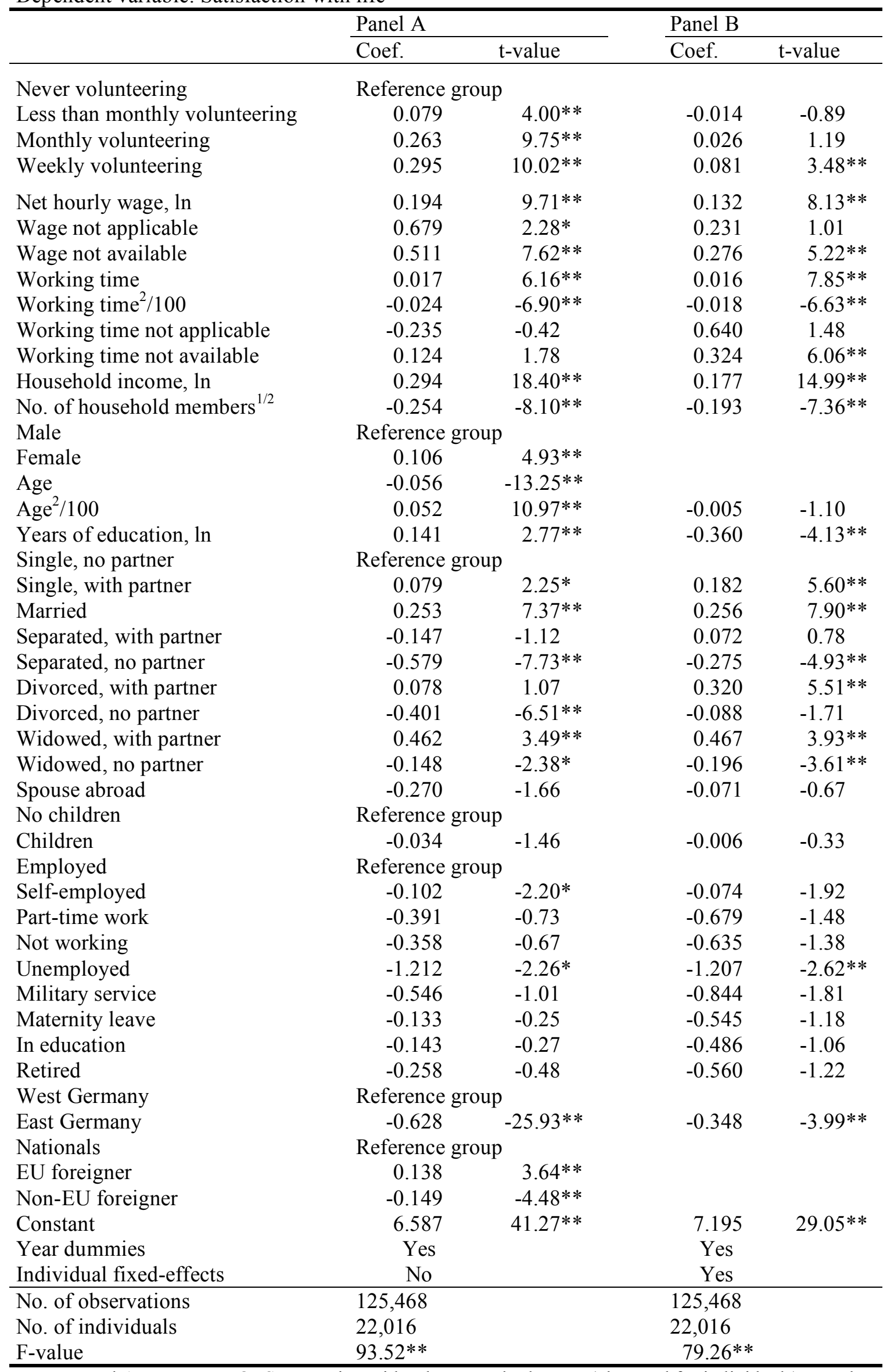

Notes: Panel A presents an OLS regression with robust standard errors (clustered for individuals). Panel 
B presents an OLS regression with individual fixed-effects.

Significance levels: $* 0.01<\mathrm{p}<0.05, * * \mathrm{p}<0.01$.

Source: German Socio-Economic Panel.

Table 2: Loss of Volunteer Work and Life Satisfaction, 1990/92

Dependent variable: Satisfaction with life

\begin{tabular}{|c|c|c|c|c|}
\hline & \multicolumn{2}{|l|}{ Panel A } & \multicolumn{2}{|l|}{ Panel B } \\
\hline & Coef. & t-value & Coef. & t-value \\
\hline Volunteering less than monthly & \multicolumn{4}{|c|}{ Reference group } \\
\hline Volunteering weekly or monthly & 0.238 & $2.12 *$ & 0.259 & $2.31 *$ \\
\hline Feeling insecure & & & -0.319 & $-4.71 * *$ \\
\hline Working time & -0.013 & -0.74 & -0.016 & -0.90 \\
\hline Working time ${ }^{2} / 100$ & 0.025 & 1.29 & 0.026 & 1.37 \\
\hline Working time not applicable & 0.212 & 0.44 & 0.118 & 0.25 \\
\hline Working time not available & -0.014 & -0.03 & -0.105 & -0.25 \\
\hline $\mathrm{Age}^{2} / 100$ & -0.098 & -1.47 & -0.065 & -0.97 \\
\hline Years of education, $\ln$ & -1.119 & -0.76 & -1.208 & -0.83 \\
\hline Single, no partner & \multicolumn{4}{|c|}{ Reference group } \\
\hline Single, with partner & -0.273 & -0.89 & -0.304 & -1.00 \\
\hline Married & 0.386 & 0.92 & 0.384 & 0.92 \\
\hline Separated, with partner & -0.534 & -0.65 & -0.563 & -0.68 \\
\hline Separated, no partner & 0.520 & 0.66 & 0.485 & 0.62 \\
\hline Divorced, with partner & -0.207 & -0.36 & -0.254 & -0.44 \\
\hline Divorced, no partner & -0.018 & -0.04 & -0.068 & -0.13 \\
\hline Widowed, with partner & 0.766 & 0.60 & 0.832 & 0.65 \\
\hline Widowed, no partner & -0.176 & -0.33 & -0.113 & -0.21 \\
\hline No children & \multicolumn{4}{|c|}{ Reference group } \\
\hline Children & -0.244 & -1.52 & -0.235 & -1.47 \\
\hline Employed & \multicolumn{4}{|c|}{ Reference group } \\
\hline Self-employed & -0.321 & -1.19 & -0.336 & -1.25 \\
\hline Part-time work & -0.739 & $-2.24 *$ & -0.745 & $-2.26^{*}$ \\
\hline Not working & -0.505 & -1.68 & -0.495 & -1.66 \\
\hline Unemployed & -0.948 & $-3.26 * *$ & -0.901 & $-3.11 * *$ \\
\hline Military service & -1.107 & -1.81 & -1.152 & -1.89 \\
\hline Maternity leave & -0.315 & -0.94 & -0.313 & -0.94 \\
\hline In education & -0.455 & -1.24 & -0.434 & -1.19 \\
\hline Retired & -0.321 & -1.19 & -0.336 & -1.25 \\
\hline Constant & 11.057 & $2.64 * *$ & 10.675 & $2.59 *$ \\
\hline Year dummy 1990 & \multicolumn{4}{|c|}{ Reference group } \\
\hline Year dummy 1992 & -0.230 & -1.85 & -0.283 & $-2.27^{*}$ \\
\hline Individual fixed-effects & Yes & & Yes & \\
\hline No. of observations & 6,489 & & 6,472 & \\
\hline No. of individuals & 3,259 & & 3,259 & \\
\hline F-value & $11.41 * *$ & & $11.66^{* *}$ & \\
\hline
\end{tabular}

Note: OLS models with individual fixed-effects.

Significance levels: $* 0.01<\mathrm{p}<0.05, * * \mathrm{p}<0.01$.

Source: German Socio-Economic Panel. 
Table 3: Intrinsic/extrinsic Life Goals and the Effect of Volunteering on Life Satisfaction

Dependent variable: Satisfaction with life

\begin{tabular}{|c|c|c|c|c|}
\hline & \multicolumn{2}{|l|}{ Panel A } & \multicolumn{2}{|l|}{ Panel B } \\
\hline & Coef. & t-value & Coef. & t-value \\
\hline Volunteering less than monthly & \multicolumn{4}{|c|}{ Reference Group } \\
\hline Volunteering weekly or monthly $(=1)$ & 0.230 & $9.81 * *$ & 0.038 & $2.09^{*}$ \\
\hline $\begin{array}{l}\text { Relative importance of extrinsic goals } \\
\text { compared to intrinsic goals }\end{array}$ & -0.129 & $-9.38^{* *}$ & & \\
\hline $\begin{array}{l}\text { Volunteering * relative importance of extrinsic } \\
\text { goals compared to intrinsic goals }\end{array}$ & -0.081 & $-3.61 * *$ & -0.049 & $-2.55^{*}$ \\
\hline Control variables (see table 1 ) & Yes & & Yes & \\
\hline Year dummies & Yes & & Yes & \\
\hline Individual fixed-effects & No & & Yes & \\
\hline No. of observations & 108,115 & & 108,115 & \\
\hline No. of individuals & 16,206 & & 16,206 & \\
\hline F-value & $94.13 * *$ & & $75.35 * *$ & \\
\hline
\end{tabular}

Notes: Panel A presents an OLS regression with robust standard errors (clustered for individuals). Panel B presents an OLS regression with individual fixed-effects.

Significance levels: $* 0.01<\mathrm{p}<0.05, * * \mathrm{p}<0.01$.

Source: German Socio-Economic Panel. 